\title{
POSSIBILIDADES DO BEM-ESTAR DOCENTE NO CONTEXTO EDUCACIONAL*
}

\author{
Silvério Costella; \\ Ingrid Kork Noal; \\ Maria Inês Naujorks \\ da Universidade Federal de Santa Maria (UFSM).
}

\begin{abstract}
REsUMo: O foco deste artigo são as reflexões sobre mal-estar docente e possibilidade do bem-estar no contexto educacional. O estudo foi realizado nas escolas públicas estaduais no município de Santa Maria - RS. A coleta de dados deu-se através de encontros, consistindo em apresentar o que está emergindo dos docentes em termos de caminhos para o bem-estar. A categoria "mal-estar" docente aparece, inicialmente, como algo externo no qual os docentes sentem-se vítimas e não como sujeitos da própria escolha, portanto, isentos de responsabilidade. No decorrer das reflexões, emergiu do grupo uma tomada de consciência em que cada um foi se reconhecendo parte do processo no qual se gerou o mal-estar, como sujeito da própria escolha. Esse insight grupal possibilitou o início da "cura" desse sentimento, cuja omissão comprometeria a saúde pessoal, bem como a consciência de que a falta de manejo do estresse colocaria em jogo o projeto profissional e existencial.

Palavras-chave: Estresse. Professor. Ensino. Bem-estar.
\end{abstract}

\section{INTRODUÇÃO}

O mal-estar docente é um fenômeno social do mundo ocidental, identificado, a partir da década de 1980, nos países desenvolvidos. Vários autores - Esteve (1999), Jesus (1998), Lipp (1996), Codo (1999), Nóvoa (1991), Mosquera (1978) e Schmidt (2000) - convergem em suas contribuições à educação para o estudo desse fenômeno. Isso permite suportar a categoria "mal-estar docente" como um fato real, presente na vida cotidiana dos

\footnotetext{
* Artigo recebido em 18/11/2012 e aprovado em 18/01/2013.
} 
professores. Segundo Jesus (1999), essa situação baseia-se no fato de que o mal-estar afeta esses profissionais, sendo inclusive considerada a docência como uma "profissão de risco" físico e mental.

O fenômeno mal-estar vem preocupando os professores que atuam em diferentes áreas e, constatado esse fato, organizou-se essa pesquisa que envolve o tema, surgindo a necessidade de uma contribuição na reflexão sobre os caminhos e possibilidades que levam o sujeito-professor ao bemestar, através do estímulo e da motivação pessoal e profissional.

A pedido das instituições escolares, realizaram-se oficinas, no município de Santa Maria-RS, sobre o bem-estar docente, com vista a contribuir para a prevenção do mal-estar, através da formação continuada dos professores da rede pública municipal e estadual. O objetivo consistiu em proporcionar reflexão, discussão e divulgação do tema mal-estar/ bem-estar docente. Efetuou-se, a princípio, uma abordagem teórica para auxiliar a compreensão da vivência do sentimento de mal-estar constituído como realidade. Após as reflexões, foi enunciada uma outra realidade que permanecia oculta até então: a possibilidade do bem-estar que foi se desvelando através de uma escuta mais profunda no discurso que emergiu dos docentes.

\section{Metodologia}

As reflexões que surgiram - nos cinco encontros realizados nas escolas públicas estaduais no município de Santa Maria - RS - foram abordadas via metodologia qualitativa. Para Minayo (1993), os adeptos da pesquisa qualitativa tentam ultrapassar o critério de objetividade e cientificidade, através de uma interpretação mais profunda do material meramente descritivo do conteúdo manifesto no discurso. Nesse sentido, através de uma escuta mais atenta, conforme Straus \& Corbin (1990), procurou-se detectar, também, conteúdos latentes, oriundos das reflexões sobre as condições da vida cotidiana do corpo docente, o que possibilitaria melhor compreensão do modo de ser desses profissionais. A intenção foi conceber uma interpretação e apreensão de uma realidade em que parece haver completa negação do ser-sujeito-profissional, bem como uma tomada de consciência para fazer emergir sentido na atividade docente, considerando as reais condições profissionais em que o sujeito está inserido e a consequente repercussão na sua qualidade de vida.

O trabalho foi organizado a partir de um programa com roteiro prédefinido das atividades a serem desenvolvidas, enfatizando-se os seguintes aspectos: a) considerações sobre o mal-estar docente (palestra inicial); e 
b) possibilidades para o bem-estar docente, através de técnicas lúdicas, afetivas e reflexivas. As atividades foram desenvolvidas em pequenos grupos, considerando-se: a realidade da comunidade escolar; o objetivo dos alunos; o objetivo da equipe diretiva; função e perfil do professor; considerações sobre os aspectos negativos e positivos do contexto escolar; sugestões para soluções conjuntas, adequadas à realidade na qual a escola está inserida; $\mathrm{e}$ construção de um compromisso social entre os participantes, por meio de constante estímulo e motivação docente.

Vivência da realidade mal-estar docente

A trajetória profissional docente nos relata as várias alterações ocorridas no seu perfil, buscando atender às exigências socioculturais que caracterizaram cada época histórica. O professor, sujeito que interage com o mundo, sofre influências que são refletidas no seu cotidiano pessoal e profissional.

Em cada momento histórico, o professor é remetido à rápida difusão de novos conceitos e valores, enfrentando dúvidas e incertezas frente ao surgimento de novos paradigmas, fazendo emergir um estado de crise em todos os setores.

Nas ciências exatas, predomina o setor econômico como gerador de uma crescente globalização da competição. Nas ciências humanas, verificase um anseio por encontrar o sentido existencial do "estar-aí", através da produção de subjetividade. Nas ciências da saúde, uma maior valorização do próprio termo saúde e a prevenção à doença, com ênfase no manejo do estresse. Contudo, a ocupação com o manejo do estresse não é mais específica à área da saúde. Hoje, fala-se de "crise", devido aos novos valores e princípios que vão sendo estabelecidos, sendo entendida como um período de transição que existe em todas as áreas, isso é, uma ruptura dos paradigmas vigentes.

Na sociedade, o docente que era valorizado e reconhecido por seu desempenho, encontra-se agora desprestigiado, questionado quanto à sua função e o sentido da sua atuação profissional. No professor, a crise ocorre devido às novas exigências profissionais que divergem radicalmente de sua formação inicial. Isso gera uma sensação de desconforto e insatisfação, por ter que se adaptar a novas circunstâncias que emergem em nível existencial e profissional. Cabe ao docente aceitar os novos desafios e adequar-se às transformações do mundo, criando, inovando, atualizando-se e, de forma especial, refletindo sobre sua prática e o contexto no qual vive. A globalização da economia e das comunicações constitui um novo cenário para os novos desafios, no qual será preciso reconstruir o saber da escola e a formação 
do professor, que deverá ser mais criativo e aprender com o aluno e com o mundo. Isso como ponto de partida essencial para metabolizar os novos desafios emergentes.

As dificuldades que norteiam o novo cenário educacional desencadeiam uma crise profissional e existencial, dificilmente superada pelo esforço pessoal. Desse modo, o mal-estar docente representa a nomenclatura mais adequada para designar a atual condição do professor frente às novas exigências. Segundo Esteve (1999), o mal-estar docente é um fenômeno social internacional, ou seja, uma doença social resultante do conjunto de reações dos professores que se percebem desvinculados das mudanças globais. A complexidade dessa temática deve ser considerada como condição básica para a compreensão das manifestações no contexto profissional docente.

O perfil docente caracteriza-se pela crise, pelo conflito consigo próprio, em que o professor questiona sua própria identidade, sua escolha profissional e sua atuação no cotidiano escolar. Também geram mal-estar: as novas e constantes exigências profissionais; a baixa remuneração salarial que repercute na qualidade de vida do professor; o novo desafio da inclusão; e o sistema escolar limitado.

O professor sente dificuldades em atender às exigências pedagógicas, permanecendo no ciclo degenerativo do mal-estar docente, que tem como fatores desencadeadores o novo perfil capitalista via processo de globalização. Conforme Demo (2008), isso constitui um desafio - em grande parte, imposto pelo mercado prepotente - a ser enfrentado pelo docente que precisa renascer a cada dia, reinventando continuamente a profissão, atendendo às demandas competitivas da globalização em constante renovação.

Também se pode destacar a indisciplina dos alunos, tema complexo que, segundo Jesus (1999), é um dos aspectos mais estressantes para o professor e que possui sua origem na massificação do ensino, quando esse passa a ser gratuito, mas obrigatório. Esse aspecto é relevante pela análise dos altos índices estatísticos que comprovam a evasão, a repetência, a violência e agressividade nos ambientes escolares.

A crise docente, pessoal e profissional, pode conduzir o professor para dois caminhos distintos. Por um lado, evidencia-se constante busca pelo bem-estar, que se caracteriza mais como possibilidade de superação da crise e aceitação do desafio. Característica comum daquele profissional que luta sem temor, com espírito competitivo e uma dose saudável de agressividade. Pela maneira de relacionar-se com o outro, sabe se defender ao se aproximar e ao se distanciar. Heidegger (1995) refere que ao se relacionar e ao se ocupar com os outros, não importa qual seja o objetivo, se faz presente a 
diferença, isso é, um intervalo. Mesmo na aproximação com o outro, o ser-aí é movido a estabelecer essa diferença sem comprometer os limites do seu próprio ser. Desse modo, intercalam-se aproximação e afastamento. Sem esse movimento de aproximação e afastamento não há relação sem comprometer o ser próprio. Existe um comprometimento desse profissional pelo excessivo envolvimento sem respeitar seus próprios limites, ou seja, sem obedecer ao movimento de aproximação e afastamento. Após determinado período nessa condição de relação, sem a devida consciência de autopreservação, surge um desencanto pela profissão, não havendo espaço para subjetivação, o que pode desencadear um processo de despersonalização. Segundo Dejours et al. (1994), esse distúrbio psicossomático ocorre em função de uma sobrecarga psíquica. Esse fato foi constatado ao se avaliar que no trabalho, em que o indivíduo permanece a maior parte do tempo, é preciso construir subjetividade e sentido através de uma relação específica entre o sujeito e a organização das atividades. Sendo o trabalho gerador de sofrimento pelo reduzido espaço para o desejo, o profissional usa mecanismos defensivos para se proteger psiquicamente contra a fadiga oriunda de sua pressão. Porém, se o sofrimento é muito intenso, sem espaço para a articulação da subjetividade e do desejo, desencadeia-se um distúrbio somático em função da sobrecarga psíquica.

A condição de mal-estar dos docentes dificulta a reconstrução subjetiva necessária para o bem-estar pessoal e profissional. Embora haja consciência da realidade em que o professor se encontra, justifica-se explorá-la melhor para possibilitar mudanças mais efetivas ao seu momento existencial. A permanência nesse estado, sem produção de subjetividade, pode comprometer o "ser próprio", a saúde psíquica desses profissionais.

\section{RESULTADOS DA PESQUISA}

À medida que as reflexões emergiam do grupo, surgia a necessidade de romper com o desconforto existencial experimentado pelos docentes. Começa a surgir a consciência de se estar perdendo, de ficar doente. É o que Esteve (1999) e Jesus (1999) nomeiam como o desejo de romper a intensidade do ciclo degenerativo em busca do bem-estar. Por outro lado, o discurso apresentado pelos docentes é acompanhado com certa passividade e falta de motivação. Segundo Schmidt (2000), vários estudos vêm sendo realizados sobre motivação profissional, apontando a escassa motivação como um dos fatores que contribuem para o abandono do trabalho, o que prejudica o equilíbrio emocional e social nas organizações. $\mathrm{O}$ declínio da motivação estende-se por todos os níveis de categoria ocupacional e faixa etária. 
Ao se constatar essa realidade, desencadeou-se nos participantes a necessidade de cada um contribuir de algum modo, a partir das próprias condições subjetivas, para a retomada do projeto docente. Progressivamente, a ideia de que prevenir o mal-estar docente deveria ser a intenção de todos foi amadurecendo, visando a busca do equilíbrio da satisfação pessoal e profissional. Através do confronto com as condições existenciais de cada professor, movido pela consciência de saber-se e sentir-se vítima em prejuízo pessoal, iniciou-se um exercício para o discernimento da própria angústia degenerativa frente ao projeto docente; um impulso do nada para um estado de ser. Um ponto de partida apenas. Enfatizou-se que a maneira de lidar com os agentes desencadeadores do estresse é individual, que varia de sujeito para sujeito, de acordo com a personalidade de cada um e de como cada sujeito percebe a situação profissional que vivencia.

As reflexões também permitiram aprimorar a capacidade de espera e tolerância (não passivas, mas ativas) nesse processo de transformação que requer uma tomada de consciência coletiva e pessoal. Enquanto consciência coletiva, o desconforto geral foi nomeado como sendo o mal-estar. Uma categoria que representa um sentimento coletivo, bem como um avanço no processo de subjetivação. O sujeito na educação tinha sido esquecido em seu ser sujeito. Segundo Stein (1988), um sujeito articulado como algo do domínio de uma suposta natureza humana. O profissional de hoje centra atenção na sua natureza humana emergente com prioridade para o bemestar e sentido existencial.

Os participantes não enfrentaram dificuldades em aceitar retomar o seu projeto profissional e avaliar as condições existenciais em seu projeto de vida. Portanto, a constatação de um desequilíbrio (um "mal-estar") impulsionou as vítimas desse processo degenerativo a identificar novas condições para aprimorar sua qualidade de vida. $E$ isso veio emergindo como prioridade. Porém, para se retomar de forma efetiva as condições existenciais, foi feita uma referência à angústia existencial em termos de angústia de finitude. Para melhor compreensão desse fenômeno, o mediador palestrante usou a expressão "choque existencial"; qualquer experiência como desapontamento pessoal, como, por exemplo, o estresse avançado, "burnout" e despersonalização, ou um paradoxal privilégio de ter tido a própria vida em risco em determinado momento da existência. Isso é, a sensação de saber que se está vivo sem sentir-se de fato vivo, ou imaginando-se antecipadamente em estado de finitude. Um exercício que fez emergir um novo estado de consciência através do discernimento para um outro modo de ser. 
Um aspecto surpreendente nos encontros, que pode ser descrito também como indicador do bem-estar, foi a grande expectativa nas reflexões. Por exemplo, a solicitação de bibliografia para continuidade da produção desse saber, sem se darem conta de que é algo produzido, sem antecedentes ou referências a serem seguidas a posteriori. Isso foi interpretado como significativo no sentido de quantificar dados e conhecimentos a respeito do assunto, ou, quem sabe, à espera de um achado, uma solução possível, mas sempre atendendo à exterioridade ou à expectativa de uma "receita" que pudesse solucionar o problema da angústia. Essa espera passiva como solução também caracteriza a categoria "mal-estar", como objeto exterior produzido pelo "outro", impessoal e institucional, devendo o mesmo ser responsabilizado. Nesse sentido, houve um esforço para a produção de um saber a partir das reflexões. Isso permitiu confronto com a verdade subjetiva através da produção de um saber inconsciente. O discurso do mediador, suposto saber consciente, foi desarticulado pelo grupo através de sua vivência e experiência como um lugar de fala e escuta, um encontro terapêutico. Embora quase imperceptível, pode-se sustentar uma redução progressiva do sentimento "mal-estar". A simples fala produziu um efeito terapêutico. O conteúdo mais expressivo da verdade subjetiva é que não mais se quer vivenciar o desconforto oriundo do mal-estar envolvendo a classe docente. A ideia de "suspensão temporária" (na fala dos pesquisadores) ou "apagão" (na fala do sujeito da pesquisa) de um estado degenerativo foi facilmente assimilada pelos participantes. Um excelente ponto de partida, não apenas intencional, mas prático, palpável e possível; isso é, através de um "basta", mesmo não tendo ainda claro o que fazer na retomada do projeto profissional e existencial.

A vontade de encontrar respostas no outro, como no mediador palestrante, denota ainda dificuldades em lidar com estratégias de manejo do estresse, permanecendo em passividade como vítima do sistema, aguardando soluções externas para o problema pessoal de mal-estar. A autorreflexão apareceu como possibilidade para encurtamento da distância da exteriorização do objeto mal-estar, em que o docente aparece como coprodutor das circunstâncias de que está sendo vítima. Tamm (1993) sustenta que o sujeito é responsável pela situação de saúde e de doença. No mesmo sentido, afirma Jesus (1999, p. 15): "a gestão do estresse profissional também depende muito do próprio professor, isso é, das estratégias de lidar com os potenciais fatores de estresses." Embora, não seja possível reverter esse processo em alguns encontros, no mesmo sentido, a tomada de consciência da omissão aparece, ainda, como um ponto de partida para mudança de 
atitude frente ao sentimento vivido. Porém, o mais importante nesse insight foi assumir, em parte, a própria "culpa" pelo mal-estar e a descoberta de que cada um também é responsável pela experiência de desconforto existencial. No sentido sartreano, a escolha que se faz implica consequências que se devem assumir como do ser próprio. Bem como não importa tanto o que fizeram do sujeito, mas o que pode ser feito daquilo que fizeram dele.

As reflexões permitiram um acordo entre os participantes que, de certo modo, constitui um pacto com a própria saúde e retomada para uma melhor qualidade de vida. Estabeleceu-se, então, que cabe a cada sujeito encontrar o seu equilíbrio pessoal e profissional, a partir do manejo do estresse e da economia libidinal. Buscou-se privilegiar um espaço para o desejo e tempo para o ócio criativo, para tornar possível um processo de subjetivação, sem comprometer a função docente. Com o aparecimento das duas categorias, "mal-estar" e "bem-estar", surgem dois sentimentos respectivos, um real e outro imaginário. $O$ sentimento de angústia aparece como uma sensação real, ao passo que a sensação de bem-estar, como um desejo apenas a ser conquistado. Pode-se vivenciar o mal-estar como uma realidade e o bem-estar como uma possibilidade. Frente à vivência do mal-estar não mais se sustenta a permanência nas lamentações das suas dificuldades cotidianas profissionais, mas na busca ativa e insistente de soluções para a sua realidade. Houve comprometimento com novas atitudes frente ao projeto de vida profissional que cada um escolheu, a partir da articulação da ação pedagógica na qual se pretendeu participar de forma ativa e responsável. Os docentes também tomaram consciência de que o estresse poderá ser bem manejado, se for aceito que, de alguma forma, também se é responsável pela realidade que nos causa sofrimento psíquico. $O$ educador não é somente influenciado pelas circunstâncias, mas também um influenciador da realidade. No momento, predomina o desconforto de uma realidade que não mais se quer que repita, ou seja, a realidade do mal-estar. Busca-se influenciar essa realidade para o seu oposto, isso é, a possibilidade do bem-estar. Dessa maneira, o profissional da educação poderá assumir sua atividade, reduzindo suas lamentações, investindo em seu desejo para a transformação da realidade, resgatando o sentido profissional e o bem-estar.

Nas reflexões, deu-se ênfase na necessidade de partir sobre o que se tem para lidar com o estresse. Um dado surge com o desapontamento do docente em encontrar, nas palestras, alternativa prática para lidar com o mal-estar. Em resposta a essa falta, as duas tendências dos profissionais caracterizadas por Horney (1984), como a tendência agressiva e a tendência condescendente - aparecem como um dado real, um fato. Na verdade, apenas 
uma tomada de consciência de algo que já se possuía, mas se agia sem o devido discernimento.

Os profissionais com tendência condescendente identificavam-se e lamentavam-se pelo "preço a ser pago" por serem assim, tendo dificuldade em lidar com a angústia, ao não se sentirem produtivos. Investem pouco em atividades de lazer. Conforme Padilha (2000), essa forma de investimento pessoal contribui para a soberania do sujeito. As pessoas condescendentes têm dificuldades de investir em tempo livre. Angustiam-se pelo excesso de cobrança em si mesmas e são comumente insatisfeitas com os resultados. Sartre (1970) sustenta que a angústia também é oriunda do próprio engajamento, não apenas no fato de ser produto das escolhas, mas ao ter que assumir os próprios atos com total e profunda responsabilidade. Para esse sujeito extremamente envolvido com a profissão, faz-se necessário um tempo para o ócio. Cuenca (2004) refere o ócio como uma área da experiência humana benéfica e com benefícios, como a liberdade de escolha, a criatividade, a satisfação, o deleite e o prazer e maior felicidade.

Os profissionais com tendência agressiva identificavam-se com menor surpresa e maior autonomia, o que realmente os caracterizou, pois, segundo Horney (1984), para esses indivíduos, a realidade externa é enfrentada como um inimigo real ou em potencial. O nível inconsciente se previne contra possível ataque ao seu ser. As relações humanas são tecidas com certa agressividade, havendo muita cautela no envolvimento emocional. O outro, em qualquer circunstância é enfrentado em nível competitivo.

No geral, do grupo da pesquisa, predominou uma tendência mais condescendente que agressiva, representada por um sujeito mais envolvido com as relações humanas, partilhando os conflitos oriundos dessa relação. Um docente mais propenso a vivenciar situações de estresse, pelo modo como se envolve em sua atividade relacional e profissional, tendo dificuldade para reconhecer os limites no envolvimento. Essa possibilidade também pode ser elucidada por Rabin et al. (1999) e Witt \& Henrich (2000), como aquela em que o profissional precisa detectar os fatores desencadeadores de estresse e identificar estratégias para o seu manejo.

A aceitação dos participantes de que essas tendências são oriundas da constituição de caráter de cada sujeito foi difícil. A caracterização do ser humano em duas principais tendências despertou neles grande interesse e imediata identificação com a tendência específica. Constituiu um dos momentos mais eficazes em termos de tomada de consciência para impedir o ciclo degenerativo do estresse, um grande insight grupal para tomada de consciência do modo como se lida com o universo existencial e psíquico. 


\section{CONCLUSÃO}

A possibilidade do bem-estar surge como tomada de consciência do "ciclo-degenerativo" no sentido coletivo e de despersonalização no nível individual. O ponto de partida para a mudança de atitude aparece como o reconhecimento de que cada um também é responsável pela doença e pela saúde pessoal. A angústia causada pelo mal-estar deixa seu sentido patológico servindo como ponto de partida para mudança do projeto existencial. Isso é, o mal-estar assume um caráter positivo, um "nada" significativo no sentido heideggeriano, como um período de transição e crescimento pessoal e profissional.

\section{POSSIBILITIES FOR TEACHERS' WELL-BEING IN THE EDUCATIONAL CONTEXT}

ABSTRACT: The article reflects on the dissatisfaction of teachers and the possibilities for well-being in the educational context. The study was carried out at State schools in the Municipality of Santa Maria, Rio Grande do Sul. Data was collected from meetings which presented what is emerging from teachers in terms of paths to well-being. The category of teachers' "dissatisfaction"initially appears as something external, in which teachers feel victims without having been subjects of their own choice, and therefore, exempt from responsibility. As the reflections progressed, an awareness emerged from the group in which the subjects recognized themselves as part of the process which generated the uneasiness, as subjects of their own choice. This group insight led to the beginning of a process of "healing", which if omitted, would damage personal health as well as the awareness that the lack of stress management strategies would prejudice the professional and existential project.

Keywords: Stress. Teacher. Education. Well-being.

\section{POSIBILIDADES DE BIENESTAR DOCENTE EN EL CONTEXTO EDUCACIONAL}

RESUMEN: El foco de este artículo está en las reflexiones sobre el mal estar docente y la posibilidad del bien estar en el contexto educacional. El estudio fue realizado en las escuelas públicas estatales en el municipio de Santa Maria, RS. La recolección de datos fue hecha a través de encuentros, consistían en presentar lo que está emergiendo de los docentes en términos de caminos para el bien estar. La categoría "mal estar" docente aparece inicialmente como algo externo, en el cual los docentes se sentían víctimas sin haber sido sujetos de su própia escogencia, por lo tanto, exentos de responsabilidad. En el transcurso de las reflexiones, surgió del grupo una toma de consciencia en la cual el individuo se fue reconociendo como parte del proceso en el que se generó el mal estar, como sujeto de su propia escogencia. Esa visión grupal posibilitó el inicio de la "cura" de ese sentimiento, cuya omisión, comprometería la 
salud personal, así como la consciencia de que la falta de manejo del estrés pondría en juego el proyecto profesional y existencial.

Palabras claves: Estrés. Profesor. Enseñanza. Bien estar.

\section{REFERÊNCIAS}

CODO, W. (Coord.). Educação, carinho e trabalho. Petrópolis: Vozes, 1999.

CUENCA, C. M. Pedagogía del ócio: modelos y propuestas. Bilbao: Universidade de Deusto, 2004.

DEJOURS, C.; ABDOUCHELI, E.; JAYET, C. Psicodinâmica do trabalho. São Paulo, 1994.

DEMO, P. O bom docente. Fortaleza: Universidade de Fortaleza, 2008.

ESTEVE, J. M. O mal-estar docente. Bauru: EDUSP, 1999.

JESUS, S. N. de. Bem-estar dos professores. Estratégias para realização e desenvolvimento profissional. Porto: Porto Editora, 1998.

JESUS, S. N. de. Como prevenir e resolver o stress dos professores e a indisciplina dos alunos? Porto: ASA Editores, 1999.

HEIDEGGER, M. Ser e tempo. Rio de Janeiro: Vozes, 1995.

HORNEY, K. Nossos conflitos interiores. São Paulo: Difel, 1984.

LIPP, M. E. N. Pesquisas sobre stress no Brasil - Saúde, ocupações e grupos de risco. Campinas: Papirus, 1996.

MINAYO, M. C. D. S. O desafio do conhecimento - Pesquisa qualitativa em saúde. São Paulo: Hucitec-Abrasco, 1993.

MOSQUERA, J. O professor como pessoa. 2. ed. Porto Alegre: Sulina, 1978.

NÓVOA, A. (Org.). Profissão professor. Porto: Porto, 1991. p. 53-70.

PADILHA, V. Tempo livre e capitalismo: um par perfeito. Campinas: Alínea, 2000.

RABIN, S.; FELDMAN, D.; KAPLAN, Z. Stress and intervention strategies in mental health professionals. British Journal of Medical Psychology, n. 72, p. 159-169, 1999.

SARTRE, J-P. O existencialismo é um humanismo. Paris: Presença, 1970.

SCHMIDT, I. T. Motivação no trabalho: teorias contemporâneas. São Paulo: Arte \& Ciência, 2000.

STEIN, E. Racionalidade e existência. Porto Alegre: LPM. 1988.

STRAUSS, J. M.; CORBIN, A. C. Basics of qualitative research. London: Sage Publications, 1990.

TAMM, M. E. Models of health and disease. British Journal of Medical Psychology, n. 66, p. 213-228, 1993. 
WITT, B. S.; HENRICH, K. T. Working smart: turning everyday commitments into scholarly outcomes. The journal of continuing education in nursing, v. 31, n. 2, 2000.

ZAGO, N.; CARVALHO, M. P.; VILELA, R. A. T. (Org.). Itinerários de pesquisa: perspectivas qualitativas em sociologia da educação. Rio de Janeiro: DP\&A, 2003.

SILVÉRIO COSTELLA: mestre em Educação pela Universidade Federal de Santa Maria.

E-mail: silveriocostella@yahoo.com.br

INGRID KORK NOAL: mestre em Educação pela Universidade Federal de Santa Maria.

E-mail: ingridschirmer@yahoo.com.br

MARIA INÊS NAUJORKS: professora de Educação na Universidade Federal de Santa Maria.

E-mail:minau@uol.com.br 